\title{
Fantasy space modeling in English academic text
}

\author{
Nadezhda N. Menshakova - Svetlana V. Shustova - Ekaterina A. Kostina - \\ Dzhafar Mallaev
}

DOI: $10.18355 / X L .2020 .13 .02 .23$

\begin{abstract}
The article is aimed at identifying the ways of representing the category of fantasy in English academic text and describing fantasy space of this type of texts. The research was carried out on the material of three monographs in linguistics. The conceptual analysis of the texts to identify contexts with markers of fantasy was undertaken, the nature of referential relationships in a fantasy utterance was studied, and the structure of fantasy was modeled. Fantasy images were considered in the light of their denotative and significative descriptors. The research findings revealed the form of representation and the functions of the category of fantasy in academic texts and displayed the peculiarity of the fantasy space in academic texts.
\end{abstract}

Key words: modeling, fantasy space, English, text, metaphor, concept, category

\section{Introduction}

"The past 20 years or so have seen increasing, and sustained, academic interest in the concept of creativity. Creativity has been explored across academic disciplines, although there is a particular focus of attention within the humanities and social sciences" (Swann, Deumet, 2017: 1). These words mark the tendency in modern social and artistic sciences and stress the idea that creativity is typical for all kind of human activity. But the role of creativity in scientific research is not truly discovered. In this paper we undertake the study of academic creativity by considering such phenomena as fantasy space of academic texts and the category of fantasy.

Modeling of fantasy space in academic texts written in English is associated with revealing the role of the category of fantasy in the process of cognition and knowledge formation which is carried out in the text. Fantasy in its broad sense is traditionally associated with artistic works. In a more narrow sense it can be associated with scientific creativity. Fantasy is a category that reflects the type of thinking and the way of world cognition and world description. The category of fantasy contributes to the implementation of the cognitive and communicative intentions of researchers, and it is a text-forming property of academic texts. This category has a sign form of expression and reflects the cognitive potential of interpretation of academic or scientific texts. The study of some academic texts in linguistics, as well as the study of some theoretical ideas on creative thinking, allowed us to model the structure of the category. Its structure consists of two components: rational and irrational. Irrational component reflects figments of researchers' imagination, ideas considered to be false, illusions, etc., and it is represented in the text by such key concepts as 'fantasy', 'fudge', 'illusion', 'mystery'. The rational component reflects different cognitive procedures used in academic research and is represented in the text by concepts 'model', 'potential', 'identification' 'interpretation', 'mental / thought experiment'. The two components of the structure 
are interlinked and it is very often not easy to distinguish one from another. The contents of the category create a special kind of fantasy space which has such properties that are only typical for a cognitive kind of texts. The complex of main components of the fantasy space, i.e. the irrational and rational components of the category of fantasy, reflects the systematic nature of fantasy images in the modeled fantasy space (Menshakova, 2015).

Since the process of academic knowledge formation is hidden from direct observation, i.e. realized in the mind of researchers, the nature and specificity of this process can be learnt only from explicit linguistic markers present in the text. Such explicit markers of new knowledge formation in the text are metaphors since they have the ability to conceptualize new ideas (Alekseeva, 1998; Mishlanova, 2002) and reflect the deep ontological meaning of cognizable academic objects. The consideration of metaphors as the main means and method of generating new knowledge is justified by their powerful modeling function (Alekseeva, 1998; Gusev, 2002). "Metaphors typically align concepts featuring different degrees of concreteness. This phenomenon has been used to claim that metaphors allow us to (better) comprehend abstract concepts" (Bolognesi, Vernillo, 2019: 26). The essential features of metaphors are their secondary nature, their high associative potential, the perceptivity of the images they create, the ability to generate new knowledge on the basis of prior knowledge (Bein, Trzewik, Maril, 2019). This makes metaphors the main means of expressing new knowledge obtained in the course of interpretation of reality.

Despite the fact that metaphorical images are the main form of actualization of the category of fantasy, fantasy images do not function in academic texts in isolation from their main conceptual meaning. The logic and cohesion of academic speech that are considered to be ontological in scientific texts (Kotyurova, 1998) prove the idea that the metaphors and other means of representing of fantasy construct a special space in the text. This space is related to the expression of cognitive and communicative intentions of the author. It is also a product of researchers' individual creative thinking, a system of images that allow recipients to understand the original academic concept.

Modeling of fantasy space helps to identify a system of fantasy images on the basis of which authors' attitude to what they say is embodied in the text. The system of fantasy images is conditioned by the internal logic of academic texts and allows us to bring out their function in the formation of academic ideas. The specificity of fantasy images is expressed in the nature of their referential correlation with objects and phenomena of reality (Menshakova, 2017). Referential or non-referential images are indicators of the potential these images have for expressing knowledge. Nonreferential, i.e. fantasy images, have a higher cognitive potential due to the fact that they provoke in the recipient more intense reflective activity and at the same time provide more freedom and hypothetical interpretation of new knowledge.

The process of modeling of fantasy space involve metaphors and formal utterances that contain non-metaphorical non-referential, i.e. fantasy, signs. Metaphorical and non-metaphorical fantasy images create a single space in academic texts. Each fantasy image has qualitative rather than quantitative characteristics.

XLinguae, Volume 13 Issue 2, April 2020, ISSN 1337-8384, ISSN 2453-711X 
The study of fantasy space thus allows us to learn what fantasy images are used in academic texts in English to realize the cognitive idea of authors and to find out how these images fulfil this goal.

The principles of fantasy space constructing depend on the cognitive and communicative intentions of authors, i.e. on what role this or that fantasy image must fulfill in the implementation of authors' intention. In other words, it is the author of academic texts who sets the rules for the functioning of images in the text created. The reflection of authors' attitude to the concept studied is expressed in referential correlation of fantasy images with reality. To establish what images are used to carry out a particular intention of the author we rely on the proposition that the system of fantasy images of academic texts reflects the structure of the category of fantasy and it is represented by two main groups of images that are correlated with the irrational and rational components of the category. The use of fantasy images in order to implement authors' cognitive design is associated with the conceptualization of new knowledge and modeling of objects of cognition. The process of theoretical modeling and the formation of new knowledge in the broader interpretation of the category of fantasy are mainly realized in the rational part of the category of fantasy.

The rational part of the fantasy space is represented by images that are dependent on the reference relationship with objects and phenomena of the real world. On the one hand, this does not allow researchers to lose touch with the object being studied, and on the other hand, it is a way of abstract studying of real object of cognition. This peculiarity of images of the rational component of the category of fantasy reflects the methodological potential of the category and proves the ability of these images to serve the goals of conceptualization and verification of new knowledge.

The irrational component of fantasy space combines mental images that are correlated with the illogical, fictional sphere of human mental activity. These fantasy images are not constrained by referential relations with objects of the real world. They have a high interpretative potential which is due to their non-referential nature. They establish ambiguous referential connection with objects of cognition or concepts studied.

The images of the irrational component, due to the lack of a strong connection between the object of comprehension and the mental fantasy image, are limited in academic texts by argumentative and persuasive functions.

Thus, the attribution of the fantasy image to an irrational or rational part of the category of fantasy, based on the nature of the reference relationship, determines the main functions of mental fantasy images in texts in linguistics. The authors' choice of images displaying referential peculiarities of rational or irrational component of the category constitutes the first stage in constructing the fantasy space of a text.

The second stage of constructing the fantasy space is possible due to the fact that both components of its structure demonstrate peculiarities of the objects of reference, i.e. the sphere of understanding of objects of reality. The peculiarities of understanding of the objects of reality are reflected in the conceptual structure of each of the two components of the category of fantasy. Their conceptual structure is related to the sphere of denotation of metaphorical images. In the process of creating a fantasy image the degree of probability of the image and the method of its creation are taken into account. A fantasy image is created according to author's general goals, be it conceptualizing of new knowledge or arguing about prior knowledge. In the first case, 
the images are subject to the theoretical procedures of modeling, abstraction, and idealization; in the second case they are based on different sources of irrational imagination.

Obviously, the main purpose of creating fantasy images is to express some kind of knowledge. Each fantasy image contains a significative dimension that represents a model of fabricated knowledge. The sphere of fantasy comprehension of academic knowledge in the text is determined by the content and the concept of the text. The study of academic texts in linguistics defines the peculiarity of the significative descriptor which is connected with linguistic and general academic knowledge.

Thus, a conceptual analysis of fantasy images in academic texts in linguistics is directed from the content to the form of expression which allows us to identify specific ways of representing fantasy images as well as to determine their function in the implementation of the author's intention.

\section{Materials and Methods}

\section{Materials}

The material for the linguistic study of the fantasy space in academic texts is represented by three monographs in linguistics written in English: R.Harris. The semantics of Science (2005); R.A. Harris. The Linguistics Wars (1993); S.Shaumyan. A Semiotic Theory of Language (1987). We believe that the ways of representing fantasy knowledge depend on the individual thinking style of authors of academic texts. This idea is grounded on the fact that academic texts reflect the peculiarities of researchers' thinking, their methods of presentation, generalization, and rethinking of academic knowledge. A practical analysis of the monographs of various researchers will help to identify the ways in which authors of academic texts formulate new knowledge or argue their position using individual fantasy images, thereby creating a special fantasy space.

\section{Methods}

The analysis of linguistic material is based on theoretical principles of text analysis. The study of the category of fantasy in the philosophical, academic, communicative and cognitive aspects allows us to consider this category as an attribute of academic texts. This category is present in academic texts because of the nature of academic cognition and the communicative nature of science.

The methodology for the analysis of the linguistic data is determined firstly, by the aim of the research, its objectives, and by the linguistic material. The study of the category of fantasy as a text-forming category is based on the analysis of the linguistic ways of its representation in the text. The aim of the analysis is identification of the ways of representing the category under study in academic texts.

Achieving this aim involves completing the following tasks:

1. To perform a conceptual analysis of the academic texts in order to identify contexts with markers of fantasy in them.

2. To study the nature of the referential relations in formal utterances with explicit fantasy markers. 
3. To model the structure of the category of fantasy in academic texts selected for the analysis.

4. To explore the form of representation and the functions of the category of fantasy.

The analysis procedure is the following. First, using the method of continuous sampling we identified contexts that contain fantasy images in the texts under study. The identification of fantasy images is based on interpretation of markers of fantasy. It was proved that fantasy is represented in academic texts mainly in the form of secondary signs, i.e. in the form of metaphors, as well as in the form of formal nonmetaphorical utterances with deviations from traditional referential relations. Metaphors and formal utterances that carry out reference to non-existent objects are considered by us as concrete units of analysis.

The main method used at the first stage of analysis is the method of logical analysis. It helps to identify contexts of use in case of ambiguity of the referent of the fantasy utterance when probabilistic nature of the fantasy sign, its polyinterpretive, ambiguous character allows us to attribute it to either the rational or the irrational component of the category of fantasy. The identification of contexts in which fantasy markers are present helped us to form a bank of units of analysis.

The next stage consists in the analysis of referential relations in contexts with fantasy markers. Contextual analysis, definitional analysis and cognitive analysis allow us to verify referential relations in the identified contexts. The nature of referential relations in fantasy utterances is the basis for classification of the knowledge they transmit as logical (and thus rational) or illogical (and thus irrational). On this ground we believe that fantasy utterances are related to: 1) the sphere of concepts of the irrational component of the category of fantasy, 2) the sphere of the rational component of the category of fantasy. The work at this stage is aimed at establishing the nature of fantasy of the conceptual space of academic texts. The nature of fantasy reflects the degree of probability of knowledge presented in the text, its ability to generate new academic ideas.

To identify peculiarities of the fantasy space created by authors of academic texts we carry out a study of the spheres of figurative identification of fantasy utterances with the object of cognition. One of the best ways to study the spheres of figurative identification of reality is a lexicographic description of metaphor (Baranov, Karaulov, 1994; Mishlanova, 2002). The linguistic material representing fantasy is analyzed with the provision that the formation of metaphorical meanings involves two semantic complexes: the significative dimension (metaphorical model) and the denotative dimension (the domain of objects of metaphorical reflection). Such analysis of metaphors allows us to answer the questions of what fantasy images are used in academic texts, what idea they represent, and how they relate to academic ideas.

\section{Results}

The identification of ways of representing fantasy in academic text written in English implies: 1) identifying the nature of fantasy image in an academic text of a particular author through the analysis of referential relations in fantasy contexts, 2) identifying 
fantasy images in utterances with recognizable objects, 3) establishing the main spheres of metaphorical modeling.

Let us consider a number of contexts of using representations of fantasy images related to the sphere of the irrational component of the category of fantasy.

(1) "...definitions do not lead us from words across the great divide to non-verbal reality" (Harris, 2005: 44).

(2) "Here we see Aristotle struggling hard to achieve levitation by tugging at the lexical bootstraps of his own vocabulary" (Harris, 2005: 40).

(3) "By this ingenious lexical manoeuvre, the world was suddenly populated by a body of like-minded investigators (henceforth to be called 'scientists'), whose existence strongly supported the view that there was a common enterprise (i.e. science) in which they were all engaged, even I they had not all realized that fact" (Harris, 2005: 28).

(4) “...the language of science was left in a kind if semantic limbo" (Harris, 2005: $171)$.

(5) "It was the search for fixed meanings that drove Plato to postulate an invisible world of eternal forms of ideas. He realized that the perceived world of everyday experience was constantly changing and calculated that behind or beyond it there must be another world of unchanging entities and relations. This invisible world was Plato's guarantee both of the possibility of genuine knowledge and, simultaneous, of the possibility of the genuine communication" (Harris, 2005: 120).

(6) "...those who hoped, by trial and error, to discover a reliable method of transmuting base metals into gold" (Harris, 2005: 51).

As can be seen from the examples considered, fantasy knowledge represented in them is based on the absence of a really existing referent. In example (4) the fantasy utterance 'semantic limbo' has a phantom referent that refers us to a fictional, mythological realm of being. In example (5) the utterance 'an invisible world of eternal forms of ideas' is non-referential. The specificity of this utterance is that, depending on the interpretation by the recipient, this utterance may acquire an abstract referent due to the fact that the idea of the invisible world of eternal forms and ideas was created in the past as an academic hypothesis. In modern science this hypothesis has been falsified and represents irrational fantasy knowledge.

The same peculiarity of the interpretation of referential relations is seen in (7):

(7) 'Plato's solution was to posit a realm of 'ideas' or 'forms', lying beyond the world of ordinary human perception. Numbers were among the inhabitants of this realm. And for Plato this timeless, unchanging realm of forms contained all the eternal exemplars behind the fleeting appearances of the everyday world" (Harris, 1993: 117).

Let us consider the following context of representation of fantasy knowledge in the irrational component of the structure of the category under study:

(8) "The identification of phonemes with bundles of distinctive features had unfortunate consequences: it induced some linguists to treat the phoneme as a fictitious entity" (Shaumyan, 1987: 65).

The word 'fiction' means "an invention of the mind", "an untrue story". This term refers to works of art or a genre of literature characterized by a description of fictional, unreal, fantastic events or phenomena. Within the academic text, the semes 
"invention of the mind" and "untrue" characterize knowledge beyond logic, in other words, knowledge turns out to be a fictitious construction of the imagination, a delusion. It is obvious that the main meaning of the concept is the absence of a true referent of the object. The meaning of the word 'fictitious', derived from the word 'fiction' also has the general meaning "lack of truth." The word 'fictitious' has the meaning "untrue", "invented", "not real". In the given context the concept 'phoneme' refers to the sphere of false non-academic knowledge. However, this idea of a phoneme is not generally accepted, the concept of a phoneme has a false referent only from the point of view of some linguists ('it induced some linguists to treat ... '). We believe that the use of concepts related to fiction and falsity of knowledge expresses the anthropocentric nature of fantasy images and is due to the individual, personal opinion of researchers about the described phenomenon.

Let us consider another context:

(9) "[Postal] argued in classes, papers, colloquia, and at the 1964 Linguistic Institute [...] that pronouns weren't "real", that they were a figment of superficial grammatical process"'(Harris, 1993: 109).

The meaning of the word 'figment' is "something believed but not real". In the given context this concept characterizes the attitude of the researcher to knowledge but not knowledge itself. However, from the speaker's perspective knowledge is considered false, hence fantasy.

Academic cognition can be characterized by the degree of falsity or fantasy of its content. Such meaning have the concepts 'figment', 'myth', etc., that are a part of the conceptual structure of the irrational component of the category of fantasy. The word 'myth' means "widely believed but false story or idea". For the concept of myth referential relations are irrelevant since "in the myth everything is possible" (LevyStross, 2005: 240). In an academic text the images characterized by this word convey the value of "false story or idea" which assesses the described phenomenon. Let us look at an example:

(10) "There are myths aplenty in linguistics these days surrounding Chomsky's spectacular rise, celebrating his brilliance and prescience, his predecessors' obtuseness and dogmatism" (Harris, 1993: 51).

In this context the word ' $m y t h$ ', i.e. a fiction that does not correspond to reality, characterizes the idea of the linguist's activity, and the use of this concept demonstrates the author's distrust to the idea. In the next context the derivative of the word ' $m y t h$ ' also characterizes the described situation as fantasy and at the same time expresses the attitude of the researcher towards it.

(11) "Rather [the Third Texas Conference on Problems of Linguistic Analysis in English] played very well to the youth of the field, Chomsky's performance at the conference occupying a substantial role in the mythology formed among the growing cadre of young transformationalists, particularly once the proceedings reached publication" (Harris, 1993: 71).

The use of the nouns 'myth' and 'mythology' in the given contexts has metaphorical nature. This nature reinforces the axiological function of these concepts. These images rather expressively evaluate knowledge.

Let us consider another context. 
(12) "[Plato's hypothetical invisible world] many people regard as an unsatisfactory solution; and rightly so, because it merely invents a mythical realm to supply a fixity that our more familiar world cannot provide" (Shaumyan, 1987: 91).

In this context the meaning of the adjective 'mythical' has a slightly different meaning than in the previous contexts. In examples (10), (11) 'myth' and 'mythology' describe erroneous ideas about something accepted by a certain society / community. In example (12), the word 'mythical' refers to a fictional world ('invents a realm'), in which laws that are different from the laws of the real world exist. This world has no denotation; it is invented, intentionally created to substitude the real world. The concept 'mythical' in this context is used to refer to a mentally constructed world. The adjective 'mythical' confirms the fantasy of knowledge and, to a lesser extent than the previous concepts, expresses the author's attitude to the ideas discussed.

Now let us consider another example of the use of the concept related to the irrational component of the category.

(13) 'Tylor begins by dismissing the old wives' tale, still frequently heard today, that in some parts of the world people cannot count as Europeans can, because after the numerals for one, two and three their language has only a general word meaning 'many'”, (Harris, 2005: 106).

The concept 'old wives' tale' means "an ancient and not necessarily true belief" and refers to the field of irrational knowledge. The main meaning of this concept is that it represents non-specialized knowledge accepted among the profane and spread through rumors. In the academic text this concept has a negative connotation and destroys the value of knowledge in relation to which it is used.

The concepts 'fudge' and 'fraud' of the irrational component of the category have a common meaning - "deceitful action". Their use in academic texts demonstrates negative assessment of the described knowledge. Consider another example:

(14) "The dubious way Aristotle goes about dealing with it (by postulating that the 'real world' is the same for all observers, whose perceptions of it are likewise identical) I shall call 'Aristotle's fudge'”' (Harris, 2005: 18).

In this context the meaning of the concept 'fudge' indicates the author' fallacy of prior academic knowledge. The author of the text does not reveal any malicious intent on the part of the creator of the false theory, but does not explicitly accept the knowledge of the opponent. The word 'fraud', which implies intentional deception unacceptable in the academic community, takes on a harsher meaning in the next context:

(15) "The publication of Reflections on Language [...] leaves little doubt that transformational-generative grammar has become an intellectual fraud" (Harris, 1993: 215).

In the context cited above the word 'fraud' has an expressive emotional connotation. It reduces the knowledge of the opponent to nothing, postulates not only its failure but also harmfulness for science.

Irrational knowledge in academic texts can be characterized by the absence, ambiguity, or non-existence of the referent. Irrational knowledge with such referents is represented in the irrational component of the structure of the category of fantasy. It is connected with such concepts as 'mystery', 'magic', 'enigma', 'prophet'. Let us look at a few examples:

XLinguae, Volume 13 Issue 2, April 2020, ISSN 1337-8384, ISSN 2453-711X 
(16) "The acquisition of a natural language by a child will remain a mystery unless we assume a hypothesis whereby there is available a simple sign system that underlies natural languages and controls their functioning" (Shaumyan, 1987: 19).

The meaning of this fantasy context can be that the process of mastering a child's natural language is not fully understood by researchers, i.e. the essence of this process is not known. However, under certain conditions ('unless we assume a hypothesis') the referent of the studied object ('acquisition of a natural language') can be detected. Consequently, fantasy images that belong to the group of concepts of 'mystery' have the potential to implement a reference relationship with objects of reality.

Consider some more examples.

(17) "In these bewildering chapters we find Aristotle reaching the mysterious conclusions that some things have an essence and others do not, and that of the things that do have an essence some are the same as their essence and others are not" (Harris, 2005: 20).

(18) "The general explanation to which their rigid deductive methodology led strikes moderns as somewhat mystical - that there is a universal grammar underlying language which is "dependent" on the structure of reality" (Harris, 1993: 14).

In both contexts the concept 'mystery' characterizes the analyzed knowledge as false or as fantasy. Describing some knowledge with the help of such concept as 'mystery' the author conveys the idea that it is impossible to verify this knowledge since 'mystery' has the meaning of "something which cannot be explained or understood". Thus, this knowledge is evaluated as erroneous. Such knowledge is considered as the one for which explanation does not matter or it is knowledge that was not clearly understood or reasoned and therefore is incomprehensible and incorrect.

The meaning of the concept 'magic' which is correlated with the irrational component of the structure of the category of fantasy allows us to evaluate the actions that it describes as inexplicable:

(19) "Katz and Postal work similar magic with imperative sentences, supplying an IMP marker which triggers the relevant transformation" (Harris, 1993: 86).

It is obvious that the general meaning of this utterance is that the actions of researchers are mysterious, logically inexplicable, and that meaning affects the assessment of the conclusions drawn. Since the actions themselves are inexplicable their results cannot be verified. The same meaning of inexplicability appears in the text with the help of the concept 'enigma'. See the contexts of its use below:

(20) 'In another way, though, the issue has less to do with Chomsky's vaunted depth of analysis than with his enigmatic choice of which particular thread of which analysis to follow at any given time" (Harris, 1993: 146).

In the given context the concept 'enigmatic choice' has no referent. In the dictionary the word 'enigma' is defined as "something mysterious and very hard to understand", which means it is not known whether there is a real referent for the phenomenon characterized by this concept. In addition, the image created by the expression 'enigmatic choice' reflects the author's attitude towards the opponent, since what is inexplicable and difficult to understand in science cannot be used as a tool for research. The opponent's actions are evaluated by the author as inapplicable to academic research, as pure fantasy. From the point of view of the author these actions have false grounds, although the concept 'enigmatic' does not exclude the possibility 
of verification and the presence of denotation. Consequently the referent of the utterance 'enigmatic choice' has potential nature.

In the following contexts the fantasy image is characterized by means of the concept 'prophet' which has no referent in the real world.

(21) "For one thing, he was known to be the student of Zellig Harris, a brilliant, somewhat eccentric, but thoroughly Bloomfieldian, and very highly regarded linguist - "perhaps the most skilful and imaginative prophet [of the period]" (Harris, 1993: 29).

(22) "The debt to Locke resurfaces when we come to the prophetic mention of science de la communication des idées" (Harris, 2005: 45).

The concept 'prophet' means a person with unrealistic, fictional power - a fantastic ability to foresee the future. It is significant that the word 'prophet' also has a seme "directed by God" which relates the named concept with both fantasy (since in the science the existence of God is denied) and faith. Due to the role that faith plays in cognition (Polany, 1998), the use of a concept related to this field in an academic context gives the utterance a positive and approving meaning.

Thus, mental images that form fantasy space of academic texts in the field of the irrational component of the structure of the category of fantasy represent the conceptual structure of this category and reflect the features of the concepts presented in it. These features consist of the absence of a reference correlation of fantasy images with objects of reality, an increased level of fantasy, and a lack of stable links with objects of research. As the result of our study we came to the conclusion that fantasy images of the irrational sphere of fantasy space in an academic text carry out mainly communicative function, i.e. serve as a means of persuasion and argumentation.

Table 1 represents the analysis of fantasy images in the irrational component of the category of fantasy on the basis of denotation.

Table 1. Denotative analysis of fantasy images in the irrational component of the category of fantasy

\begin{tabular}{|c|c|}
\hline fantasy & $\begin{array}{l}\text { There were a few frothing publications, like Ray Dougherty's (1974) } \\
\text { "Generative Semantics Methods: A Bloomfieldian Counterrevolution," and } \\
\text { an exchange between Katz and McCawley that saw titles like } \\
\text { "Interpretative Semantics Meets Frankenstein" (1976) and } \\
\text { "Interpretative Semantics Meets the Zombies" (LW 154). } \\
\text { Since Bloomfield had become the absolute Bogey Man of linguistics, and } \\
\text { since the generative semantics seemed to be working within the same } \\
\text { general framework, it took a while for these accusations to surface (LW } \\
\text { 161). }\end{array}$ \\
\hline fudge & $\begin{array}{l}\text { So, mentalism in psychology and linguistics went the way if vitalism in } \\
\text { biology, phlogiston in chemistry, ether in physics, and, also like those } \\
\text { other concepts, mentalism packed its bags when it left }(L W 26) \text {. }\end{array}$ \\
\hline illusion & $\begin{array}{l}\text { Sound is the hard currency; meaning is the network of cultural and } \\
\text { formal conventions that turns it into a stick of gum at the candy store ( } L W \\
\text { 5). }\end{array}$ \\
\hline & consistent, more simple systen \\
\hline
\end{tabular}

XLinguae, Volume 13 Issue 2, April 2020, ISSN 1337-8384, ISSN 2453-711X 


\begin{tabular}{|l|l|}
\hline $\begin{array}{l}\text { confidence, looking, in many ways, for a messiah. } \\
\text { And perhaps linguistics, as an abstract and collective entity, was looking } \\
\text { for a savior (LW 36). } \\
\text { MIT was a stronghold of truth and wisdom in language studies, Chomsky } \\
\text { was the uniformly acknowledged intellectual leader, Aspects was the new } \\
\text { scripture. } \\
\text { The central, defining concern of the work codified, extended, and enriched } \\
\text { in that scripture was to get beneath the literal surface of language and } \\
\text { explore its subterranean logical regularities, to find its deep structures, to } \\
\text { get at meaning (LW 101). }\end{array}$ \\
\hline
\end{tabular}

Now let us consider a number of contexts representing fantasy in the rational sphere of the structure of the category of fantasy:

(23) “...the crude promises that weight-watchers consume for their intellectual diet is the rhetoric telling us that science has discovered in DNA a concealed 'genomic language' that can be compared directly to English" (Harris, 2005: x).

(24) 'We are asked to believe that the genome is 'a lexicon', a collection of arbitrary ordered sentences, similar to the arbitrary alphabetical order of entries in an encyclopaedia" (Harris, 2005: x).

(25) “...describe the language of science 'from the outside "” (Harris, 2005: viii).

(26) "words may be instruments of communication they may also be obstacles to understanding" (Harris, 2005: 43).

(27) “degrees or levels of reality" (Harris, 2005: 208).

(28) "It is always possible [...] imagine a larger box enclosing any given box, however large. 'In this way space appears as something unbounded', (Harris, 2005: 191).

(29) "a hypothetical 'ideal speaker-hearer"” (Harris, 2005: 99).

(30) "the social dimension of science" (Harris, 2005: 27).

(31) "the current academic story about 'superstrings", (Harris, 2005: 176).

(32) "living in a universe with 'ten dimensions"” (Harris, 2005: 176).

(33) "hard-science [linguistics]" (Harris, 2005: 174).

(34) "soft science" (Harris, 2005: 174).

These contexts reveal the specificity of the rational component of the category of fantasy. The general characteristics of the concepts typical for the category are determined by the methods and procedures used in science to search for new knowledge, to conceptualize and interpret it. The main concepts of the rational component of the category of fantasy are 'model', 'potential', 'identification', 'mental' / thought experiment', 'interpretation'. They have abstract referents that are correlated with real-life but idealized objects. This fact is due to the nature of science which studies only real-life objects and phenomena.

All the given contexts represent models of academic cognition, context (24) also demonstrates the process of formation and interpretation of new fantasy knowledge, contexts (28) and (29) reflect the high hypothetical value of images.

Let us consider the specifics of the rational component of fantasy relying on the main groups of concepts making up its structure.

The process of academic modeling can be considered as virtual since it is carried out not in reality but in the mental space of human thinking. According to H.R. 
Schmidtke, it is a property of language to model reality: "human language is a versatile tool for communicating mental models between speakers of a language"(Schmidtke, 2020: 27). Psychologists claim that understanding of the world is built on modelling because our brain "reflects the external world causal relationships in the form of a logically consistent and prognostic model of reality" (Vityaev 2019). Modeling is an operation with an ideal object of study, i.e. with an object that has an abstract referent. The operation of modeling needs fantasy thinking. In context (35) "Academic attempt to model reality" (Harris, 1993: 214) the object of modeling is reality. The concept of reality is abstract in nature which determines the effect of fantasy produced by the utterance 'to model reality'. Physical manipulation of reality is generally impossible, and due to the depth of the concept even mental modeling of reality may be incomplete. Likewise in context (36) "Every language presents its own model of the Universe" (Shaumyan, 1987: 11) the model of the universe does not reflect all existing features and characteristics inherent in it, the referent of the utterance 'model of the Universe' is abstract since it is intentionally constructed in the mental space of the researcher and displays only the most relevant signs of the object of study. To study the individual sides of such complex objects as reality, the universe, etc., modeling is an important theoretical tool. Modeling is considered from the standpoint of probabilistic logic where it is possible to "cut off" irrelevant characteristics and multiple interpretations of the obtained data when studying objects or phenomena of reality (Krymsky, 1974). This means that fantasy images created in the process of modeling objects of reality have a high interpretative potential.

The processes of abstraction and idealization are reflected in the images of the rational sphere of fantasy space. Objects that undergo abstraction and idealization in science have abstract referents since they relate to complex, systemic, indivisible objects of cognition the study of which is possible when we avoid their specific, unambiguous characteristics.

Let us consider the contexts:

(37) "Therefore, the starting point of this theory is the phonemic level as an ideal system of distinctive oppositions whose properties are determined by the Principle of Semiotic Relevance. The ideal system of distinctive oppositions is not based on analytic procedures but is postulated as a theoretical construct from which possible systems of distinctive oppositions are deduced" (Shaumyan, 1987: 83).

(38) "The concept of language is an abstraction that characterizes the common properties of all languages" (Shaumyan, 1987: 1).

In context (37) the referent of the word 'language', which is the object of study, is transformed in such a way that it correlates with many other similar objects. Fantasy in this case is revealed in the researcher's ability to comprehend existing objects as concrete and abstract entities at the same time.

The concepts of the rational component of the fantasy 'potential', 'possible', 'hypothetical', etc. are joined in one group due to the general trait of probability of the referent, its potential and virtual character.

Fantasy images related to the sphere of the concept 'potential' are characterized by the fact that their referent is assigned to the future, it exists in the abstract form and may or may not be realized in reality:

XLinguae, Volume 13 Issue 2, April 2020, ISSN 1337-8384, ISSN 2453-711X 
(39) "These superpositions can be explained as a realization of a potential of natural languages for developing symmetrical constructions" (Shaumyan, 1987: 179).

Images correlated with the sphere of the concept 'hypothetical' have referents that are supposed by researchers but not confirmed by science at the moment.

Objects with ambiguous referents, existing and non-existent at the same time, are used in science to solve logical problems, to verify knowledge, etc. The hypothesis is associated with virtual modeling of an object or phenomenon which, due to its ideal nature, can only have an abstract referent existing in a virtual world. Consider the context:

(40) "At this point in the exposition, Einstein allows a hypothetical objector to protest” (Harris, 2005: 137).

The concept ' $a$ hypothetical objector' represents a mentally created object, a mental interlocutor, an opponent, a representative of competing theory and logic. The attributive use of the word 'hypothetical' characterizes the object but does not evaluate it from the standpoint of reality - unreality. The main function of using the concept in this context is to conceptualize the knowledge necessary for the successful development and argumentation of the theory.

The concept 'identification', which is part of the rational component of the category of fantasy, reveals the property of fantasy images to create similarities between objects or phenomena.

The identification process is based on establishing the relation $\mathrm{A}=\mathrm{B}$. In this sense, the identification process is similar to the process of conceptually superimposing the system of characteristics of one object on another. In other words, the identification of two objects implies that of one of them has a referent that partially coincides with the referent of another object that belongs to another subject area. Since the referents of ideal objects modeled by science are abstract and ambiguous, the referential relations established between the studied and the known objects are also abstract. Let us consider the contexts:

(41) "Under the definition of the grammatical category proposed above, ergativity is identical with agentivity if we define the meaning 'agent' as a class of meaning characterized by the same coding devices as the syntactic function 'ergative," (Shaumyan, 1987: 149).

The concept 'interpretation' represents one of the important procedures of academic research and processing academic data. In academic texts the concept 'interpretation' has an ambiguous referent which is explained by the nature of the process of interpretation that allows many truths. Here is a context from another text:

(42) "As another glance at the Floyd tree will show, Postal's reductionist campaign was gathering a good deal of stream - adjectives were re-analyzed as deep verbs, adjective phrases disappeared at deep structure, some nouns were also deep verbs, prepositions and conjunctions were deep verbs, prepositional phrases dissolved at deep structure, tenses were deep verbs, quantifiers were deep verbs, articles arose transformationally, the verb phrase dissolved at deep structure - and abstract syntax arrived at a convenient little core of deep categories: NPs, Vs, and Ss" (Harris, 1993: 115).

Each of the objects mentioned in the context (grammatical parts of speech) has at least two referents. The adjective has a virtual object representing the abstract structure of all adjectives known as a referent. In the theory of transformational grammar, as is 
seen from Harris's narration, the referent of the adjective changes because the theoretical idea of its origin and function changes. Thus, the word 'adjective' in this context has two referents: the one that the author of the text keeps in mind and the other is implied by transformational grammar. From the point of view of the author, the second referent is false; from the position of transformational grammar, the first referent is false. Fantasy thinking in the process of data interpretation manifests itself as a creative ability to identify potential properties of objects, as well as evaluate these properties from the perspective of new knowledge.

The concept 'mental / thought experiment' represents a scientific operation related to the use of fantasy to obtain scientific knowledge about the subject being studied. A thought experiment is used in scientific research when an object is not available for direct study. In an academic text, fantasy knowledge represented by the concept 'mental / thought experiment' has a virtual referent and can be verified by probabilistic logic. Referents of imaginary objects or situations involved in a thought experiment have phantom or abstract existence.

Let us consider a broad context of a thought experiment:

(43) "The antinomy of transposition is generated by the following two assumptions, which both characterize the essential properties of the phoneme.

Assumption 1: Phonemes are elements whose function is to differentiate between signs. [...]

If assumption 1 is valid, then the acoustic substance of phonemes can be transposed into other forms of physical substance - graphic, chromatic, tactile.

Any phoneme and any set of distinctive features can be presented not only as acoustic elements but as graphic, chromatic, or tactile symbols, as well. In order to see that, let us perform the following mental experiment. We will transpose phonemes into circles of identical dimension but different colour, let us say in English the vowel æ into a blue circle, the vowel e into a brown circle, the consonant t into a yellow circle. The words cat, ten, neck, net, can, tan can then be represented as chains consisting of combinations of the differently colored circles..." (Shaumyan, 1987: 51).

The given thought experiment is based on a conscious violation of normal referential relations in the utterance. The basis for the representation of the concept 'mental/ thought experiment' in this text is a conceptual blend that combines the spheres of acoustic and visual perception. The researcher transforms objects of study (phonemes), changes the form of their material representation from acoustic to visual. The choice of such transformation from an acoustic form to a visual one is called for by the highest productivity of visual perception (Ryabtseva, 2005). As a result of this transformation phonemes acquire an additional visual form of expression. However, this form of expression is imaginary; it was proposed only for the purpose of implementing the experiment and does not imply further existence. Accordingly, the assumption that words can be represented as chains of circles of different colors is false. The utterance 'transpose ... the vowel æ into a blue circle' is possible in terms of probabilistic logic which means it has a virtual referent. Understanding of the modification proposed by the author is possible due to the person's ability to fantasy, to use probabilistic logic in the process of comprehension of the utterance. As can be seen from the context, probabilistic logic plays a significant role in construction and understanding of thought experiments, and it allows us to understand false utterances viewed as such from the standpoint of traditional logic.

XLinguae, Volume 13 Issue 2, April 2020, ISSN 1337-8384, ISSN 2453-711X 
Thus, the mental images that form the fantasy space of the English academic text in the sphere of the rational component of the structure of the category of fantasy represent the conceptual structure of this category and reflect the peculiarities of the concepts presented in it. The peculiarity of the concepts consists in the fact that fantasy images belonging to the rational component of the category have abstract or ambiguous referents that link these fantasy images with virtual objects created by researchers in ideal mental form. The nature of fantasy created by the peculiarities of referential relations in the rational component of the structure of the category is lower than in its irrational component. Fantasy images of the rational sphere of fantasy space primarily perform a modeling function and participate in the conceptualization of new knowledge.

Table 2 represents the analysis of fantasy images in the rational component of the category of fantasy on the basis of denotation.

Table 2. Denotative analysis of fantasy images in the rational component of the category offantasy

\begin{tabular}{|c|c|}
\hline model & $\begin{array}{l}\text { Dummy terms serve to resolve the conflict between syntactic and } \\
\text { semantic requirements: since dummy terms have null meaning, } \\
\text { they do not change the semantic context of an impersonal } \\
\text { sentence, and at the same time they allow satisfaction of the } \\
\text { structural requirement that every sentence must have a subject } \\
\text { (Shaumyan 1987: 228). }\end{array}$ \\
\hline potential & $\begin{array}{l}\text { At this point in the exposition, Einstein allows a hypothetical } \\
\text { objector to protest (Harris, 2005: 132) }\end{array}$ \\
\hline identification & $\begin{array}{l}\text { In short, logic brought the abstract syntacticians much closer to } \\
\text { the mentalist goals which they had swallowed with their early } \\
\text { transformational milk. } \\
\text { Along with vitamin M, mentalism, their early transformational } \\
\text { milk included another essential nutrient, especially after } \\
\text { Chomsky's tour de force linkage of his program to the goals of } \\
\text { traditional grammar, vitamin } \boldsymbol{U} \text {, universality, and in Aspects } \\
\text { Chomsky associated this nutrient with one specific module of his } \\
\text { grammar, the base component [...] (Harris, 1993: 117). }\end{array}$ \\
\hline interpretation & $\begin{array}{l}\text { As another glance at the Floyd tree will show, Postal's } \\
\text { reductionist campaign was gathering a good deal of stream - } \\
\text { adjectives were re-analyzed as deep verbs, adjective phrases } \\
\text { disappeared at deep structure, some nouns were also deep verbs, } \\
\text { prepositions and conjunctions were deep verbs, prepositional } \\
\text { phrases dissolved at deep structure, tenses were deep verbs, } \\
\text { quantifiers were deep verbs, articles arose transformationally, the } \\
\text { verb phrase dissolved at deep structure - and abstract syntax } \\
\text { arrived at a convenient little core of deep categories: NPs, Vs, and } \\
\text { Ss (Harris, 1993:115). }\end{array}$ \\
\hline $\begin{array}{l}\text { mental/thought } \\
\text { experiment }\end{array}$ & $\begin{array}{l}\text { "It is perfectly possible to imagine a universe in which any act of } \\
\text { counting by being in it annihilated some members of the class } \\
\text { counted during the time and only during the time of its } \\
\text { continuance. [...] For I would see that it is also imaginable that } \\
\text { those accustomed to attending meetings of the Council of Nicaea } \\
\text { might learn to develop a different method of counting from mine: a }\end{array}$ \\
\hline
\end{tabular}




\begin{tabular}{|l|l|}
\hline $\begin{array}{l}\text { method that accommodated the alarming propensity of bishops to } \\
\text { become indistinguishable from their immediate neighbours. For } \\
\text { instance, in this method there might be a numeral 318/9, which } \\
\text { was neither } 318 \text { nor } 319 \text { in my familiar system. Given this more } \\
\text { sophisticated Nicaean system of numeration, I would see that the } \\
\text { question 'Are there really } 319 \text { bishops of only 318?' becomes } \\
\text { pointless: and perhaps meaningless, since the logic of one-to-one } \\
\text { correlation no longer applies. Creating such a universe, with a } \\
\text { different basis for the integration of counting, and a different } \\
\text { mathematics, would be well within the capacities of the Demiurge } \\
\text { (Harris, 2005: 187). }\end{array}$ \\
\hline
\end{tabular}

The study of the three monographs in linguistics allowed us to carry out the analysis of fantasy images on the basis of significative descriptors. In the studied works the main significative descriptors belong to the sphere of language, linguistics, researchers, communication, science, academic work, thought, knowledge, world and components of academic cognition (see Table 3).

Table 3. Significative descriptors of fantasy images of the category of fantasy in monographs "The semantics of Science" by R.Harris (2005), "The Linguistics Wars" by R.A. Harris (1993), “A Semiotic Theory of Language” by S.Shaumyan (1987).

\begin{tabular}{|l|l|}
\hline LANGUAGE & $\begin{array}{l}\text { "the kernel was the seed of meaning in } \\
\text { transformational grammar" (Harris, 1993: 48) } \\
\text { "grammatical pieces of language" (Harris, 1993: 57) } \\
\text { "domain of meaning" (Harris, 1993: 12) } \\
\text { "looking underneath language" (Harris, 1993: 81) } \\
\text { "grammaticality was a wholly syntactic beast" } \\
\text { (Harris, 1993: 188) } \\
\text { "interpretive semanticists took only a conservable, } \\
\text { tasteless, nutritionless little nibbles from ... language" } \\
\text { (Harris, 1993: 8) }\end{array}$ \\
\hline LINGUISTICS & $\begin{array}{l}\text { "cross-pollination [in generative semantics]" (Harris, } \\
\text { "the linguistic battle" (Harris, 1993: 121) } \\
\text { "Hallean phonology was ... a product of a fantastic } \\
\text { never-never land" (Harris, 1993: 60) } \\
\text { "language [is] a path running from sound to meaning, } \\
\text { and ... linguistics [is] the exploration of that path" } \\
\text { (Harris, 1993: 12) } \\
\text { "generative light bulb surely clicked on" (Harris, } \\
1993: 52)\end{array}$ \\
\hline RESEARCHER & $\begin{array}{l}\text { "four leading figures all on their semantic horses" } \\
\text { (Harris, 1993: 131) } \\
\text { "Chomsky is a steadfast champion of creativity" } \\
\text { (Harris, 1993: 57) }\end{array}$ \\
\hline
\end{tabular}

XLinguae, Volume 13 Issue 2, April 2020, ISSN 1337-8384, ISSN 2453-711X 


\begin{tabular}{|c|c|}
\hline & $\begin{array}{l}\text { "grammar-zombies" (Harris, 1993: 53) } \\
\text { "[Chomsky] is many linguists" Great Satan" (Harris, } \\
\text { 1993: 54) } \\
\text { "Noam is not a human being. He is an angel" (Harris, } \\
\text { 1993: 77) }\end{array}$ \\
\hline COMMUNICATION & $\begin{array}{l}\text { "the knowledge inside a language user's head" } \\
\text { (Harris, 1993: 100) } \\
\text { "breadth of knowledge" (Harris, 1993: 15) } \\
\text { "to model knowledge of space" (Harris, 1993: 32) }\end{array}$ \\
\hline SCIENCE & $\begin{array}{l}\text { "science is a full-blooded activity" (Harris, 1993: 214) } \\
\text { "empirical science camp" (Harris, 1993: 5) } \\
\text { "the anomalist camp" (Harris, 1993: 13) } \\
\text { "blessing of science" (Harris, 1993: 11) } \\
\text { "various bits of theoretical machinery" (Harris, 1993: } \\
\text { 194) }\end{array}$ \\
\hline ACADEMIC WORK & $\begin{array}{l}\text { "[Chomsky's] writing can be ... forbidding as a } \\
\text { blackberry patch, full of fruit you can see but you just } \\
\text { can't get to" (Harris, 1993: 244) } \\
\text { "Sapir's [Language] ... heaped high with brilliant } \\
\text { insights and imaginative leaps" (Harris, 1993: 22) } \\
\text { "Bloomfield's [Language] is a cookbook, ... giving } \\
\text { its readers recipes with which to obtain similar } \\
\text { results" (Harris, 1993: 22) } \\
\text { "[Chomsky's Logical Structure of Linguistic Theory] } \\
\text { looked to be the iceberg of which Syntactic Structures } \\
\text { formed the tip" (Harris, 1993: 69) } \\
\text { "Halle's evangelical Seven Sermons on Sounds in } \\
\text { Speech" (Harris, 1993: 69) }\end{array}$ \\
\hline THOUGHT & $\begin{array}{l}\text { "the territory of thought" (Harris, 1993: 6) } \\
\text { "the deer park of the mind" (Harris, 1993: 53) } \\
\text { "genetic veins in the marble of our minds" (Harris, } \\
\text { 1993: 66) } \\
\text { "the golden realm of thought" (Harris, 1993: 96) } \\
\text { "a thought [looks like] the bundles of features hanging } \\
\text { down from the bottoms of deep structure" (Harris, } \\
\text { 1993: 108) }\end{array}$ \\
\hline KNOWLEDGE & "road to knowledge" (Harris, 2005: 39) \\
\hline WORLD & $\begin{array}{l}\text { "the hidden structures of creation" (Harris, 1993: 12) } \\
\text { "corrosive passage of time" (Harris, 1993: 15) }\end{array}$ \\
\hline $\begin{array}{l}\text { COMPONENTS OF } \\
\text { ACADEMIC COGNITION }\end{array}$ & $\begin{array}{l}\text { "a cloud-like subatomic model" (Harris, 1993: 7) } \\
\text { " } \Delta \text {-nodes "functioned as an Open Sesame" to } \\
\text { generative semantics" (Harris, 1993: 90) }\end{array}$ \\
\hline
\end{tabular}




\section{Conclusions}

The main objective of the practical study of the category of fantasy in English academic texts was to identify and analyze the linguistic, cognitive and communicative features of the representation of this category. To achieve this goal it was necessary to model the fantasy space of the academic texts in linguistics written in English.

The methodology of modeling the fantasy space of an academic text is based on the ideas of 1) a complex, ambiguous structure of the category of fantasy, which is represented by two opposite components: rational and irrational; 2) on the predominantly metaphorical form of representation of fabricated knowledge in academic texts. At modeling fantasy space it is necessary to take into account the dual structure of the category of fantasy, the degree of correspondence of the referent of the metaphor with the reality, and the nature of fantasy of each of the components of fantasy space. Recognition of the predominantly metaphorical way of expressing fantasy knowledge makes it possible to study the ways of representing fantasy from the perspective of its denotative description.

The analysis of the system of images represented in the irrational component of the structure of the fantasy category showed that the specifics of the representation of fantasy knowledge is determined by the conceptual structure of each of the components of the category. Mental fantasy images of the irrational sphere of the fantasy space of the text are characterized by referential relationships with the objects of reality that they represent. This determines the predominantly argumentative and persuasive functions of irrational images in academic texts. The system of fantasy images of the rational component of the category of fantasy is characterized by the presence of an abstract referent that correlates the fantasy image with the object of cognition. The object of cognition is constructed by researchers and exists in a virtual, ideal form in their mind. This feature of fantasy images of the rational component of the category determines their function to conceptualize new academic knowledge.

The study of the denotative and significative spheres of fantasy images showed the following. 1) The denotative sphere of fantasy space is represented by the basic concepts included in the structure of the irrational and rational components of the category of fantasy. Such concepts are: 'fantasy', 'fudge', 'illusion', 'mystery' for the irrational component, and 'model', 'potential', 'identification', 'interpretation', 'mental / thought experiment' for the rational component of the structure of the category of fantasy. 2) The significative sphere of fantasy space represents the main areas of linguistic and general academic knowledge. Such areas in the studied English academic texts in linguistics were LANGUAGE, LINGUISTICS, RESEARCHER, COMMUNICATION, SCIENCE, KNOWLEDGE, ACADEMIC WORK, COMPONENTS OF ACADEMIC COGNITION, THINKING, PEACE.

The main linguistic ways of representing fantasy knowledge in academic texts are metaphors and non-metaphorical formal utterances containing non-referential signs or images. The main function performed by metaphors in academic texts is conceptualization of new academic knowledge. It is realized in the sphere of the rational component of the category of fantasy. In the sphere of the irrational component the metaphor serves the purpose of realizing the communicative intention of the author and performs primarily argumentative and persuasive functions. Non- 
metaphorical formal utterances contain fantasy knowledge that relates them either to the sphere of the irrational component of the category of fantasy (in this case, they are associated with the concepts 'fudge' or 'illusion') or to the sphere of the rational component of the category where they are represented by the concepts 'interpretation' or 'mental / thought experiment'.

\section{Bibliographic references}

ALEKSEEVA, L.M. 1998. Term and Metaphor. Perm: Perm University, 250 p. (In Russian)

BARANOV, A.N. - KARAULOV, YU. N. 1994. The Dictionary of Russian Political metaphors. Moscow: Pomowsky and Partners. 330 p. (In Russian)

BEIN, O. - TRZEWIK, M. - MARIL, A. 2019. The role of prior knowledge in incremental associative learning: An empirical and computational approach // Journal of Memeory and Language. 107. pp. 1-24.

BOLOGNESI, M. - VERNILLO, P. 2019. How abstract concepts emerge from metaphorical images: The metonymic way // Language and Communication, 69. pp. 26-41.

GUSEV, S.S. 2002. The Meaning of Probable. Connotation Semantics. St. Petersburg: Alteya. 192 p. (In Russian)

HARRIS, R. 2005. The semantics of Science. London - New York: Continuum. 219 p. ISBN 0826478476

HARRIS, R.A. 1993. The Linguistics Wars. New York - Oxford: Oxford University Press. 356 p. ISBN 0-19-507256-1

KOTYUROVA, M.P. 1988. On Extralinguistic Grounds of Semantic Structure of Scientific Text (Functional and Stylistic Aspect). Krasnoyarsk: Krasnoyarsk University . 171 p. (In Russian)

KRYMSKY, S.B. 1974. Scientific knowledge and the Principles of its Transformation. Kiev: Naukova Dumka. 210 p. (In Russian)

LEVY-STROSS K. 1994. Primitive Thinking. Moscow. (In Russian)

MENSHAKOVA, N.N. 2015. Representation of Fabricated Knowledge in Academic texts. In: Russian Linguistic Bulletin, vol. 4, n. 4, pp. 24-25.

MENSHAKOVA, N.N. 2017. The Use of Non-Referential Words in Academic Texts. In: Russian Linguistic Bulletin, № 3(11). P. 55-57.

MISHLANOVA, S.L. 2002. Metaphor in Medical Discourse. Perm: Perm University. 160 p. (In Russian)

POLANI, M. 1998. Personal Knowledge. On the Way to Post-critical Science. Blagoveschensk: BGK named after I.A. Baudouin de Courtenay (In Russian)

RYABTSEVA N.K. 2005. Language and Natural Intellect. Moscow, Academia. 240 p. (In Russian)

SCHMIDTKE, H.R. 2020. TextMap: A general purpose visualization system. In: Cognitive Systems Research. 59. pp. 27-36.

SHAUMYAN, S.A. 1987. Semiotic Theory of Language. Bloomington and Indianapolis: Indiana University Press. 352 pp. ISBN 0-253-30472-5

SWANN, J. - DEUMET, A. 2017. Sociolinguistics and language creativity. In: Language Sciences. XXX. pp. 1-8.

VITYAEV, E. 2019. Consciousness as a logically consistent and prognostic model of reality, Cognitive Systems Research doi: https://doi.org/10.1016/j.cogsys.2019.09.021

Words: 9462

Characters: 61313 (34,06 standard pages)

assoc. prof Nadezhda N. Menshakova

Perm State University 
Perm

Russia

ORCID ID: https://orcid.org/0000-0002-3874-7279

mnesperanza@mail.ru

prof. Svetlana V. Shustova

Perm State University

Perm

Russia

ORCID ID: https://orcid.org/0000-0002-8318-7864

lanaschust@mail.ru

assoc. prof. Ekaterina A. Kostina

Novosibirsk State Pedagogical University

Novosibirsk

Russia

ORCID ID: http://orcid.org/0000-0002-1428-7095

ea_kostina@mail.ru

prof. Dzahafar Mallaev

Dagestan State Pedagogical University

Makhachkala

Russia

ORCID ID: https://orcid.org/0000-0001-7084-7627

Vip.dgaf@mail.ru 